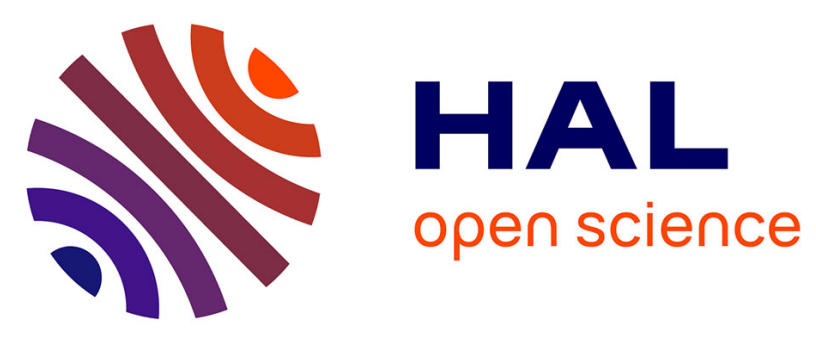

\title{
Significance of methicillin-teicoplanin resistant in bloodstream infections in patients of the Semmelweis University hospitals in Hungary
}

K. Kristóf, E. Kocsis, D. Szabó, S. Kardos, V. Cser, K. Nagy, P. Hermann, F.

Rozgonyi

\section{To cite this version:}

K. Kristóf, E. Kocsis, D. Szabó, S. Kardos, V. Cser, et al.. Significance of methicillin-teicoplanin resistant in bloodstream infections in patients of the Semmelweis University hospitals in Hungary. European Journal of Clinical Microbiology and Infectious Diseases, 2011, 30 (5), pp.691-699. 10.1007/s10096-010-1142-5 . hal-00658697

\section{HAL Id: hal-00658697 https://hal.science/hal-00658697}

Submitted on 11 Jan 2012

HAL is a multi-disciplinary open access archive for the deposit and dissemination of scientific research documents, whether they are published or not. The documents may come from teaching and research institutions in France or abroad, or from public or private research centers.
L'archive ouverte pluridisciplinaire HAL, est destinée au dépôt et à la diffusion de documents scientifiques de niveau recherche, publiés ou non, émanant des établissements d'enseignement et de recherche français ou étrangers, des laboratoires publics ou privés. 


\section{Significance of methicillin - teicoplanin resistant Staphylococcus}

\section{haemolyticus in bloodstream infections in patients of the}

\section{Semmelweis University hospitals in Hungary}

K. Kristóf, E. Kocsis, D. Szabó, S. Kardos, V. Cser, K. Nagy, P. Hermann, F. Rozgonyi

K. Kristóf *, E. Kocsis

Division of Microbiological Diagnostic Laboratory, Central Clinical Laboratory, Semmelweis University, H-1089, Nagyvárad tér 4. Budapest, Hungary

e-mail:krikat@net.sote.hu

D. Szabó, S. Kardos, V. Cser ${ }^{* *}$ K. Nagy

Institute of Medical Microbiology, Semmelweis University, Budapest, Hungary

${ }^{* * *}$ Present work place: Microbiology Diagnostic Laboratory, United Saint István and Saint László Municipal Hospital, Budapest, Hungary

P. Hermann

Department of Prosthodontics, Semmelweis University, Budapest, Hungary

F. Rozgonyi

Microbiology Laboratory, Department of Dermatology, Venerology and Dermatooncology,

Semmelweis University, H-1085 Budapest, Mária u. 41. Hungary

*Correspondence to:

Katalin Kristóf, MD, PhD 
Phone: +3612106467 or +36208259816

Fax: + 3612100278

Email: krikat@net.sote.hu

Key words: Staphylococcus haemolyticus, methicillin-teicoplanin resistance, clonal distribution, bloodstream infection 


\section{Abstract}

The purposes of this study were to quantify the impact of Staphylococcus haemolyticus in the epidemiology of the blood stream infection (BSI) and to characterize the rates and quantitative levels of resistance to antistaphylococcal drugs. During an eight-year period, 2967 BSIs of the patients hospitalized in different clinical departments of the Semmelweis University, Budapest, Hungary were analyzed. 184 were caused by S. haemolyticus amounting to $6 \%$ of all infections. The antibacterial resistance of S. haemolyticus isolates was investigated by the broth microdilution method, vancomycin agar screen, population analysis profile and PCR for $m e c A$, vanA and $v a n B$ genes detection. Epidemiological investigation was processed by determining of phenotypic antibiotic resistance patterns and PFGE profiles. Extremely high MIC levels of resistance were obtained to oxacillin, erythromycin, clindamycin, gentamicin and ciprofloxacin. The incidence of teicoplanin reduced susceptibility revealed $32 \%$ without possessing either the vanA or vanB gene by the strains. PFGE revealed 56 well-defined genotypes indicating no clonal relationship of the strains. The propensity of $S$. haemolyticus to acquire resistance and its pathogenic potential in immunocompromised patients, especially among preterm neonates emphasise the importance of species level identification of coagulase-negative staphylococci and routinely determine the MIC of proper antibacterial agents for these isolates.

\section{Introduction}

Bacterial bloodstream infections (BSIs) are a major cause of morbidity and mortality. The frequency of these infections, their epidemiology and the invading organisms have changed with the emergence of an increasingly ill, immune-compromised population of hospitalized patients and with using more medical support and indwelling devices. 
The greater role of Gram-positive cocci as causative agents of nosocomial BSIs was highlighted by many huge studies from all over the world. Together with Staphylococcus aureus, the coagulase-negative staphylococci (CoNS) were the most frequent bacterial blood-stream isolates analysing the data of different surveillances [1-6]. However, their role as a real cause of morbidity and mortality is difficult to ascertain. BSIs caused by CoNS do not result in excess mortality, but they lead to both increased rates of morbidity and longer hospitalization and higher overall cost of treatment. Several studies have showed Staphylococcus epidermidis to be the dominant species among CoNS isolated from human blood cultures, and Staphylococcus haemolyticus at the second place [5-12]. In addition, a large proportion of nosocomial CoNS isolates from patients treated in intensive care units has proven to be resistant to a number of antibiotics, including penicillinase-stable penicillins [1216]. Therefore, cyclic glycopeptides (vancomycin and teicoplanin) have been recommended as first empirical therapeutic agents for such serious staphylococcal infections. Moreover, being a potential pathogen, S. haemolyticus can also serve as a donor of resistance genes to the more virulent staphylococcal species such as S. aureus. S. haemolyticus was the first Gram-positive pathogen to acquire glycopeptide resistance [17-19], earlier than any other Staphylococcus and Enterococcus species, and has been suggested to be unique among CoNS being predisposed to develop glycopeptide resistance. In a recent investigation Takeuchi et al. analyzed the complete genome sequence of multidrug-resistant strains of S. haemolyticus demonstrating that it contains 82 IS127. IS elements seems to contribute to the ability of these microorganisms to acquire drug resistance [20]. Recently many studies have analyzed the possible virulence factors of S. haemolyticus, especially biofilm-production [21-22], as an early study showed S. haemolyticus strains to produce compact colonies in soft agar and to possess peculiar hydrophobic cell surfaces [23]. 
We have recently observed notable number of $S$. haemolyticus strains causing colonisation and severe infections in the patients of the Intensive Care Units (ICUs) of the Semmelweis University Hospitals. Especially worrisome has been the increased number of S. haemolyticus strains with reduced susceptibility to teicoplanin among bloodstream isolates from newborns treated at the neonatal intensive care units.

The aims of our study were (i) to quantify the impact of $S$. haemolyticus in the epidemiology of the BSIs among patients treated at the University Hospitals of the Semmelweis University between 2001 and 2008, (ii) to determine the rates and quantitative levels of resistance of $S$. haemolyticus strains to antistaphylococcal drugs, (iii) to reveal epidemic phenotypic antibiotic resistance patterns, (iiii) to examine correlations between PFGE genotypes and phenotypic resistance patterns.

\section{Material and methods}

\section{Sources of strains}

During the years 2001-2008 a total of 2967 BSIs of the patients hospitalized in different departments of the Semmelweis University, Budapest, Hungary were analyzed on the basis of blood culture results. Because the interpretation of a CoNS blood culture isolate as a pathogen or contaminant is problematic, relatively stringent criteria were used to determine their etiologic role. Isolates from blood cultures were judged to be involved in the infection if they represented the only microorganism isolated from the blood in the presence of clinical signs or symptoms of sepsis. Among adult patients the isolation of the same CoNS species with a similar biotype and antimicrobial susceptibility profile from at least two blood cultures were regarded as evidence of true BSI. Only the first invasive isolate per patient was considered in this study. Since the neonatologists obtained only a single blood culture from an infant with 
suspected sepsis in more than $70 \%$ of the cases, positive cultivation result from blood culture of these patients was always verified by a clinician.

\section{Taxonomic identification of strains}

S. haemolyticus strains were identified by the VITEK system (bioMérieux, Lyon, France) according to the manufacturer's instructions. They were stored at $-80^{\circ} \mathrm{C}$ with $25 \%$ glycerol for subsequent phenotypic and genotypic examinations.

\section{MIC determination}

Quantitative antibiotic resistance levels of the strains were measured by determining the minimal inhibitory concentrations (MICs) of oxacillin, vancomycin, teicoplanin, erythromycin, clindamycin, gentamicin, sulfamethoxazole-trimethoprim, doxycycline, ciprofloxacin, and linezolid with the reference broth microdilution method in cation supplemented Mueller-Hinton broth using break points according to guidelines of NCCLS earlier and those of later Clinical Laboratory Standards Institute (CLSI) [24].

\section{Determination of antibiotic resistance pattern}

Resistance phenotypes of the $S$. haemolyticus strains were defined through a number representing the number of antibiotics to which the strain was resistant to any of oxacillin, erythromycin, clindamycin, gentamicin, sulfamethoxazole-trimethoprim, doxycycline and ciprofloxacin as well as with a letter subscript indicating the particular combination of antibiotics to which the isolate was resistant. Isolates showing an intermediate sensitivity were classified as resistant. Non-sensitivity to glycopeptides was not considered in this differentiation, because of the determination of their efficiency requires more special investigation methods. Multidrug-resistance was defined as resistance to oxacillin and at least to two antibiotic classes other than $\beta$-lactams.

\section{Investigation of resistance to glycopeptides}

Beside the determination of MIC level of vancomycin and teicoplanin vancomycin screen agar were also used according to the CLSI guidelines [24]. Modified population analysis 
profiles (PAPs) also were done [25], to determine heteroresistance to vancomycin among $S$. haemolyticus strains. Every test sample run was accompanied by using the Mu3 and ATCC 29213 S. aureus strains as controls. A ratio was then calculated by dividing the area under curve (AUC) of the test strain by the AUC of Mu3. PAP-AUC criteria for the determination of vancomycin resistance, glycopeptide-intermediate Staphylococcus spp. (GIS) and the hetero-GIS (hGIS) are as previously described and are based on multiple tests with Mu3: $\leq 0.9=$ methicillin-resistant Staphylococcus spp; 0.9-1.3=hGIS, and $\geq 1.3=$ GIS [26].

\section{Amplification of methicillin resistance gene (mecA)}

Methicillin resistance was confirmed by showing the presence of mecA gene in the strains with PCR method [27]. Amplifications were performed in a Progene Techne thermocycler (Techne).

\section{Detection of glycopeptides resistance genes}

Because a good number of $S$. haemolyticus strains showed reduced susceptibility to teicoplanin, vanA and $v a n B$ were searched in the strains by the method described by DutkaMalen et al. [28].

\section{Determination of clonality of the strains by Pulsed-Field Gel Electrophoresis (PFGE)}

PFGE was executed by an internal protocol modified for CoNS [29]. S. haemolyticus strains were grown overnight on blood agar plates at $37^{\circ} \mathrm{C}$ and DNA was release from the cells by using lysostaphin-lysis (Sigma). DNA was digested with SmaI (Promega, Madison, WI, USA) at $25^{\circ} \mathrm{C}$ for $3 \mathrm{~h}$. PFGE was performed in $1 \%$ agarose gel (Bio-Rad) using a CHEF-DRII apparatus (Bio-Rad) in TBE buffer (1X Tris-borate-EDTA, pH:8.3,(Bio-Rad). Lambda DNA PFGE Marker (BioLabs, Budapest, Hungary) was used as size standards in the first lane on each gel. Electrophoresis conditions were $14^{\circ} \mathrm{C}$ for $21 \mathrm{~h}$, with pulse time ranging from 5 to $60 \mathrm{sec}$ at an angle of $120^{\circ}$, voltage was $6 \mathrm{~V} / \mathrm{cm}$. Gels were stained with a solution of ethidium bromide (Sigma) and digitalized with UVItec (Pharmatia Biotech) equipment. The DNA band 
patterns obtained were analyzed visually and with the aid of Diversity Database software, version 2.2.0 (Bio-Rad). Dendrograms were created using UPGMA clustering of a similarity matrix based on band-matching Dice coefficients (tolerance 1\%, optimization 1\%). Isolates showing indistinguishable or closely related band patterns $(\leq 6$ band differences, $>80 \%$ similarity) were regarded as possibly clonally related as suggested by Tenover et al. [30].

\section{Results}

\section{Frequency of S. haemolyticus in bloodstream infections}

According to Table 1 the vast majority of BSIs were caused by Gram-positive microorganisms during the examination period (41\%-68\%). S. haemolyticus caused approximately $6 \%$ of all infections and $11 \%$ of all the Gram-positive episodes. Overall 184 BSIs were caused by $S$. haemolyticus in patients with clinical signs of sepsis treated at different hospital wards of the Semmelweis University. S. haemolyticus was the second most common cause of CoNS bacteremia (after S. epidermidis) and ranging between $12 \%$ and $26 \%$ of all CoNS isolates in different years. However, considerable differences were observed when the distribution of $S$. haemolyticus isolates was compared according to different departments (Table 2). In patients treated in the two independent Neonatal Intensive Care Units (NICU) almost $18 \%$ and $15 \%$ of the bloodstream isolates were S. haemolyticus, while 4 $\%$ of the BSI isolates were S. haemolyticus from the patients of the "adult" intensive care units. Surgical departments were characterised by 5-6\% S. haemolyticus BSI, whereas 0-3\% of the bloodstream isolates from internal medicine or other patient wards belonged to this species.

\section{Antibacterial sensitivity patterns of isolates}

$97 \%$ of the S. haemolyticus isolates exhibited phenotypical oxacillin resistance. PCR amplification showed the presence of $m e c A$ gene in each of these strains. The resistance to erythromycin, clindamycin, gentamicin, sulfamethoxazole/trimethoprim and ciprofloxacin 
was $96 \%, 62 \%, 87 \%, 49 \%$, and $84 \%$ respectively, with evenly high MIC levels during the investigation period (Table 3). No inducible MLSB phenotype was found among erythromycin resistant and clindamycin sensitive strains. Every strain was sensitive to linezolid and the resistance rate to doxycycline was surprisingly low (15\%). All of the isolates were vancomycin-sensitive according to the criteria of the CLSI, but $32 \%$ of them had a vancomycin MIC of $2 \mathrm{ug} / \mathrm{ml}$. None of the strains formed resistant colonies on $6 \mu \mathrm{g}$ vancomycin per $\mathrm{ml}$ agar plate under the special incubation conditions. None of the strains showed heteroresistance to vancomycin at $1 \mu \mathrm{g} / \mathrm{ml}$ determined by the modified population analysis profiles, but among the strains showed $2 \mu \mathrm{g} / \mathrm{ml}$ vancomycin MIC, $45 \%$ were hGIS and $36 \%$ GIS. MICs of teicoplanin were $1-8 \mu \mathrm{g} / \mathrm{ml}$ (susceptible) for $68 \%$ of the strains; 16 $\mu \mathrm{g} / \mathrm{ml}$ (intermediate) for $18 \%$ of the strains; and $32-\mu \mathrm{g} / \mathrm{ml}$ (resistant) for the rest $14 \%$ of the strains. None of teicoplanin resistant strains contained vanA or vanB genes investigated by PCR.

\section{Antibiotic resistance patterns}

In an attempt to use the phenotypical antibiotic resistance profile as an epidemiological marker, we defined resistance phenotypes through a number and a letter as described in the Materials and Methods. Altogether 33 distinct resistance phenotypes were found, $96 \%$ of the isolate showed multi-resistance. Among them, as Table 4 shows, six phenotypes were considered as epidemic patterns amounting to $78 \%$ of all $S$. haemolyticus strains. Occurrences of other resistance patterns were under $1 \%$ (data not shown). Our analysis revealed that $5 \%$ of all the strains were resistant to all antibacterial agents except glycopeptides and linezolid. $25 \%$ of the strains were resistant to six antimicrobial agents, 39 $\%$ to five, $22 \%$ to four, $5 \%$ to three and just $3 \%$ of the strains to none or two different antimicrobial agents. Many strains showing the same antibiotic resistance pattern were isolated from different, structurally non-connected wards of the university hospital wards, 
while many with different antibiotic resistance patterns were identified from the same ward (data not shown).

\section{Clonal relationship of the strains}

The PFGE patterns were characterised by 12-19 bands ranging from 40 to $600 \mathrm{~kb}$. Fifty-six well-defined profiles of genomic DNA after SmaI digestion were obtained from 184 S. haemolyticus strains. According to the criteria of Tenover et al. [30], 27 PFGE types and 29 subtypes were found. These 29 subtypes were associated with 11 types of the 27 main types. 27 types displayed similarity coefficients from $25-80 \%$; each was coded with a number. Each subtype was coded with a letter (similarity $\geq 80 \%$ ). Fig. 1 exhibits the dendrogram resulting from the computer-assisted analysis of the PFGE profiles of all 56 distinct pattern-types. It proves the genetic heterogeneity of the strains after SmaI digestion. Many strains showing the same PFGE type or subtype were isolated from patients treated in different, structurally nonconnected wards of the university hospital, while many different PFGE types or subtypes were identified from patients in the same ward. There was no correlation between antibiotic resistance phenotypes and PFGE genotypes.

\section{Discussion}

Our data clearly show the increasing importance of Gram-positive cocci among bloodstream isolates during the last years, as this re-emergence has been found in other publications as well [1, 2, 4, 31-32]. Of them, S. haemolyticus strains constituted $6 \%$ of all bloodstream isolates in our study and appeared to be more prevalent in intensive care units, especially in those for neonates, than in the other departments. Our data harmonize with results of many studies from all over the world [4-8, 12, 19, 33], when authors indicated that S. haemolyticus accounted for 5-38\% of all CoNS clinical isolates. The unique specificity reflects on the fact that some patients, e.g. critically ill ones receiving many invasive therapeutic interventions in 
ICUs have a higher risk to becoming colonized or infected. Specially, premature newborns are at the highest risk for $S$. haemolyticus infections.

The vast majority of the $S$. haemolyticus strains in our collection were multidrug-resistant. However, the multiple resistances in these S. haemolyticus strains were proved not to be uniform. Several phenotypical resistance patterns were found with four relatively frequent types characterized by a simultaneous resistance to oxacillin, erythromycin, gentamicin, and ciprofloxacin. It is clinically important, that $97 \%$ of BSI isolates contained the mecA gene, resulting in a very high level of oxacillin, consequently $\beta$-lactam resistance, which is unusual in the literature $[7,9,14]$. Our other alarming finding is the $14 \%$ teicoplanin resistance with 4 $\mu \mathrm{g} / \mathrm{ml} \mathrm{MIC}_{50}$ and $32 \mu \mathrm{g} / \mathrm{ml} \mathrm{MIC} \mathrm{M}_{90}$. This means that teicoplanin cannot be considered any longer as first line drug against $S$. haemolyticus infection in this country. Our results support the suggestion, that vancomycin remains the only available agent that is still active in both empirical and susceptibility testing based treatment of severe infections caused by methicillinteicoplanin-resistant S. haemolyticus. With our screening method none of the S. haemolyticus isolates proved to be resistant to vancomycin using CLSI criteria, but $32 \%$ of them had an MIC of $2 \mu \mathrm{g} / \mathrm{ml}$ for vancomycin.

The problem is more serious, if we reanalyse our results using recent EUCAST guidelines (www.eucast.org) for the determination of glycopeptide resistance. $37 \%$ of all $S$. haemolyticus strains were resistant to teicoplanin (MIC $>4 \mu \mathrm{g} / \mathrm{ml}$ ) according to EUCAST guidelines. Added to this, our results also show that the heteroresistance to vancomycin investigated by the modified population profile analysis is high. Among the sensitive strains (with MIC of $2 \mu \mathrm{g} / \mathrm{ml}$ ) the occurrence of strictly sensitive strains (PAP AUC < 0.9) was just $19 \%$. Recently several reports have focused on the emergence of vancomycin-resistant $S$. 
haemolyticus isolates, which have shown a stepwise increase in vancomycin therapy, but the true clinical significance of this phenomenon is not clear [12, 18-19, 34-37].

Our data indicate that doxycycline and linezolid may be effective against a part of the multidrug-resistant $S$. haemolyticus strains and also used for empiric therapy beside vancomycin, but the clinical significance of these findings should be investigated further in the future.

The PFGE analysis of our clinical isolates of S. haemolyticus from blood cultures revealed heterogeneous PFGE patterns with no predominant genotype. This fact indicates that we examined many genotypically different strains, not subcultures of the same strain, thus our conclusions are valid for the S. haemolyticus species itself. Our results also confirm other reports with regard to the large genomic variability presented by S. haemolyticus [38-39]. Some studies revealed typically high genetic homogeneity, if the isolates were "outbreakstrains", came from the same unit of the hospital [31]. Our strains showed no correlation between the phenotypical antibiotic resistance patterns and PFGE genotypes. Because of these data and because of the multiresistance of S. haemolyticus, the antibiotic resistance patterns are not useful for epidemiological investigation and characterization.

It is absolutely clear that surveillance programmes are necessary to identify changes in the spectrum of microbial pathogens causing serious infections and to monitor trends in antimicrobial resistance patterns in both nosocomial and community-acquired infections [9, 30, 40]. Since $S$. haemolyticus seems to be a unique species among CoNS, it is mandatory to identify CoNS isolates causing BSI to species level. However, a large number of studies failed to do so $[12,41]$. Species identification of CoNS would have clinical and epidemiological interest for the clinicians. This situation is similar to what we found in fungal infections, namely Candida krusei means fluconasole-resistance, and S. haemolyticus means 
oxacillin-and very probably teicoplanin-resistance. In addition, multi-resistant $S$. haemolyticus being a potential pathogen and a resident member of normal bacterial flora of the skin may also serve as a donor of resistance genes to other species particularly to the more virulent $S$. aureus [42-44]. Thus intra- and interspecies transfer of resistance genes should be seriously considered.

This is the first survey on the S. haemolyticus species from Hungary and its teicoplanin resistance. The propensity of $S$. haemolyticus to acquire resistance and its pathogenic potential in immunocompromised patients emphasise the importance of species level identification of CoNS and routinely determine the MIC of proper antibacterial agents for these isolates, and then, to investigate the epidemiology. Further studies are required to evaluate the significance of different virulence and host factors contributing to the pathogenesis of S. haemolyticus sepsis.

\section{Acknowledgements}

This work was supported by the Hungarian National Scientific Research Found (OTKA) Grant No: T32473, M36764 and T46186 to Ferenc Rozgonyi.

\section{References}

1. Fluit AC, Verhoef J, Schmitz FJ (2001) Frequency of isolation and antimicrobial resistance of Gram-negative and Gram-positive bacteria from patients in intensive care units of 25 European University hospitals participating in the European Arm of the SENTRY Antimicrobial Surveillance Program 1997-1998. Eur J Clin Microbiol Infect Dis 20:617-625

2. Decousser JW, Pina P, Picot F, Delalande C, Pangon B, Courvalin P, Allouch P (2003) Frequency of isolation and antimicrobial susceptibility of bacterial pathogens isolated from patients with bloodstream infections: a French prospective national survey. J Antimicrob Chemother 51:1213-1222 
3. Karchmer AW. (2000) Nosocomial bloodstream infections: organisms, risk factors, and implications. Clin Infect Dis 2000, 31 Suppl 4: S139-143

4. Natoli S, Fontana C, Favaro M, Bergamini A, Testore GP, Minelli S, Bossa MC, Casapulla M, Broglio G, Beltrame A, Cudillo L, Cerretti R, Leonardis F (2009) Characterization of coagulase-negative staphylococcal isolates from blood with reduced susceptibility to glycopeptides and therapeutic options. BMC Infect Dis 9:83

5. Souvenir D, Anderson DE, Palpant S, Mroch H, Askin S, Anderson J, Claridge J, Eiland J, Malone C, Garrison MW, Watson P, Campbell DM (1998) Blood cultures positive for coagulase-negative staphylococci: antisepsis, pseudobacteremia, and therapy of patients. J Clin Microbiol 36:1923-1926

6. Klinkenberg C, Rønnestad A, Anderson AS, Abrahamsen TG, Zorman J, Villaruz A, Flaegstad T, Otto M (2007) Persistent strains of coagulase-negative staphylococci in a neonatal intensive care unit: virulence factors and invasiveness. Clin Microbiol Infect $11: 1100-1111$

7. Petinaki E, Kontos F, Miriagou V, Maniati M, Hatzi F, Maniatis AN (2001) Survey of methicillin-resistant coagulase-negative staphylococci in the hospitals of central Greece. Int J Antimicrobiol Agents 18:563-566

8. Isaac DW, Pearson TA, Hurwitz CA, Patrick CC (1993) Clinical and microbiologic aspects of Staphylococcus haemolyticus infections. Pediatr Infect Dis J 12:1018-1021

9. Low DE, Schmidt BK, Kirpalani HM, Moodie R, Kreiswirth B, Matlow A, Ford-Jones EL (1992) An endemic strain of Staphylococcus haemolyticus colonizing and causing bacteraemia in neonatal intensive care unit patients. Pediatrics 89:696-700

10. Perl TM, Krüger WA, Houston A, Boyken LD, Pfaller MA, Herwaldt LA (1999) Investigation of suspected nosocomial clusters of Staphylococcus haemolyticus infections. Infect Control Hosp Epidemiol 20:128-131 
11. Szewczyk EM., Piotrowski A, Rózalska M (2000) Predominant staphylococci in the intensive care unit of a paediatric hospital. J Hosp Infect 45:145-154

12. Tabe Y, Nakamura A, Oguri T, Igari J (1998) Molecular characterization of epidemic multiresistant Staphylococcus haemolyticus isolates. Diagn Microbiol Infect Dis 32: $177-183$

13. Koksal F, Yasar H, Samasti M (2009) Antibiotic resistance patterns of coagulasenegative staphyloccus strains isolated from blood cultures of septicemic patients in Turkey. Microbiol Res 164:404-410

14. John MA, Pletch C, Husain Z (2002) In vitro activity of quinipristin/dalfopristin, linezolid, telithromycin and comparator antimicrobial agents against 13 species of coagulase-negative staphylococci. J. Antimicrobial Chemother 50:933-938

15. Sanches SI, Mato R, de Lencraste H, Tomasz A (2000) Patterns of multidrug resistance among methicillin-resistant hospital isolates of coagulase-positive and coagulase-negative staphylococci collected in the international multicenter study RESIST in 1997 and 1998. Microb Drug Resist 6:199-211

16. Nunes APF, Teixeria LM, Iorio NLP, Bastos CCR, Fonseca LS, Souto-Padrón T, Santos KRN (2006) Heterogeneous resistance to vancomycin in Staphylococcus epidermidis, Staphylococcus haemolyticus and Staphylococcus warneri clinical strains: characterisation of glycopeptide susceptibility profiles and cell wall thickening. Int J Antimicr Agents 27:307-315

17. Biavasco F, Vignaroli C, Varaldo PE (2000) Glycopeptide resistance in coagulasenegative staphylococci. Eur J Clin Microbiol Infect Dis 19:403-417

18. Froggatt JW, Johnston JL, Galetto DW, Archer GL (1989) Antimicrobial resistance in nosocomial isolates of Staphylococcus haemolyticus. Antimicrob Ag Chemother $33: 460-466$ 
19. Rodrigez-Aranda A, Daskalaki M, Villar J, Sanz F, Otero JR, Chaves F (2009) Nosocomial spread of linezolid-resistant Staphylococcus haemolyticus infections in an intensive care unit. Diagn Microbiol Infect Dis 63:398-402

20. Takeuchi F, Watanabe S, Baba T, Yuzawa H, Ito T, Morimoto Y, Kuroda M, Cui L, Takahashi M. Ankai A, Baba S, Fukui S, Lee JC, Hiramatsu K (2005) Whole genom sequencing of Staphylococcus haemolyticus uncovers the extrem plasticity of its genome and the evolution of human-colonizing Staphylococcal species. J Bacteriol $187: 7292-7308$

21. Fredheim EG, Klingenberg C, Rohde H, Frankenberger S, Gaustad P, Flaegstad T, Sollid JE (2009) Biofilm formation by Staphylococcus haemolyticus. J Clin Microbiol $47: 1172-1180$

22. de Silva GDI, Kantzanou M, Justice A, Massey RC, Wilkinson AR, Day NPJ, Peacock SJ (2002) The ica operon and biofilm production in coagulase-negative staphylococci associated with carriage and disease in a neonatal intensive care unit. $J$ Clin Microbiol 40:382-388

23. Godó ZI, Magyar E, Andirkó I, Rozgonyi F (1997) Compact growth of Staphylococcus haemolyticus in soft agar is not due to hydrophobic interaction between the cocci. Acta Microbiol Hung 44:343-349

24. Clinical and Laboratory Standards Institute (CLSI) (2008) Performance standards for antimicrobial susceptibility testing; Eighteenth informational supplement M100-S19. CLSI, Wayne, PA

25. Walsh TR, Bolmström A, Qwärnström A, Ho P, Wootton M, Howe RA, MacGowan AP, Diekema D (2001) Evaluation of current methods for detection of staphylococci with reduced susceptibility to glycopeptides. J Clin Microbiol 39:2439-2444 
26. Wootton M, Howe RA, Hillman R, Walsh TR, Bennett PM, MacGowan AP (2001) A modified population analysis profile (PAP) method to detect hetero-resistance to vancomycin in Staphylococcus aureus in a UK hospital. J Antimicrob Chemother 47:399-403

27. Ünal S, Hoskins J, Flokowich JE, Wu CYE, Preston DA, Skatrud PL (1992) Detection of methicillin-resistant staphylococci by using the polymerase chain reaction. J Clin Microbiol 30:1685-1691

28. Dutka-Malen S, Evers S, Courvalin P (1995) Detection of glycopeptide resistance genotypes and identification to the species level of clinically relevant enterococci by PCR. J Clin Microbiol 33:24-27

29. Bradford R, Abdul Manan R, Daley AJ, Pearce C, Ramalingam A, D'Mello D, Mueller Y, Uahwatanasakul W, Qu Y, Grando D, Garland S, Deighton M (2006) Coagulase-negative staphylococci in very-low-birth-weight infants: inability of genetic markers to distinguish invasive strains from blood culture contaminants. Eur $\mathbf{J}$ Clin Microbiol Infect Dis 25:283-290

30. Tenover FC, Arbeit RD, Goering RV, Mickelsen PA, Murray BE, Persing DH, Swaminathan B (1995) Interpreting chromosomal DNA restriction patterns produced by pulsed-field gel electrophoresis: criteria for bacterial strain typing. J Clin Microbiol $33: 2233-2239$

31. Björkqvist M, Söderquist B, Törnqvist E, Sjöberg L, Fredlund H, Kühn I, ColqueNavarro P, Schollin J (2002) Phenotypic and genotypic characterisation of blood isolates of coagulase-negative staphylococci in the newborn. APMIS 110:332-339

32. Nunes APF, Teixeria LM, Bastos CCR, Silva MG, Ferreira RBR, Fonseca LS, Santos KRN (2005) Genomic characterization of oxacillin-resistant Staphylococcus 
epidermidis and Staphylococcus haemolyticus isolated from Brazilian medical centres. J Hosp Inf 59:19-26

33. Jarløv JO, Høiby N (1998) Coagulase-negative staphylococci in a major Danish university hospital: diversity in antibiotic susceptibility between wards. APMIS $106: 411-416$

34. Blans M, Troelstra A (2001) Glycopeptide resistance in Staphylococcus haemolyticus during treatment with teicoplanin. Infect Control Hosp Epidemiol 22:263-264

35. Schwalbe RS, Stapleton JT, Gilligan PH (1987) Emergence of vancomycin resistance in coagulase-negative staphylococci. N Eng J Med 316:927-931

36. Menezenes GA, Harish BN, Sujatha S, Vinothini K, Parija SC (2008) Emergence of vancomycin-intermediate Staphylococcus species in southern India. J Med Microbiol $57: 911-912$

37. Wilson AP, O’Hare MD, Felmingham D, Grüneberg RN (1986) Teicoplanin-resistant coagulase-negative staphylococcus. Lancet 2(8513):973

38. Burnie JP, Naderi-Nasab M, Loudon KW, Matthews RC (1997) An epidemiological study of blood culture isolates of coagulase-negative staphylococci demonstrating hospital-acquired infection. J Clin Microbiol 35:1746-1750

39. Raimundo O, Heussler H, Bruhn JB, Suntrarachun S, Kelly N, Deighton MA, Garland SM (2002) Molecular epidemiology of coagulase-negative staphylococcal bacteraemia in a newborn intensive care unit. J Hosp Inf 51:33-42

40. Gradelski E, Valera L, Aleksunes L, Bonner D, Fung-Tomc J (2001) Correlation between genotype and phenotypic categorization of staphylococci based on methicillin susceptibility and resistance. J Clin Microbiol 39:2961-2963

41. Tacconelli E, Tumbarello M, Donati KG, Bettio M, Spanu T, Leone F, Sechi LA, Zanetti S, Fadda G, Cauda R (2001) Glycopeptide resistance among coagulase- 
negative staphylococci that cause bacteraemia: epidemiological and clinical findings from a case-control study. Clin Inf Dis 33:1628-1635

42. Tabe Y, Nakamura A, Igari J (2001) Glycopeptide susceptibility profiles of nosocomial multiresistant Staphylococcus haemolyticus isolates. J Infect Chemother 7:142-147

43. Berglund C, Söderquist B (2008) The origin of a methicillin-resistant Staphylococcus aureus isolates at a neonatal ward in Sweden - possible horizontal transfer of a staphylococcal cassette chromosome mec between methicillin-resistant Staphylococcus haemolyticus and Staphylococcus aureus. Clin Microbiol Infect $11: 1048-1056$

44. Hanssen AM, Kjelden G, Sollid JUE (2004) Local variants of staphylococcal cassette chromosome mec in sporadic methicillin-resistant Staphylococcus aureus and methicillin-resistant coagulase-negative staphylococci: Evidence of horizontal gene transfer? Antimicrob Ag Chemother 48:285-296 


\section{Figure}

Figure 1 - Dendogram resulting from the computer-assisted analysis of the PFGE profiles of

56 distinct pattern-types. The scale represents average percentages of similarity

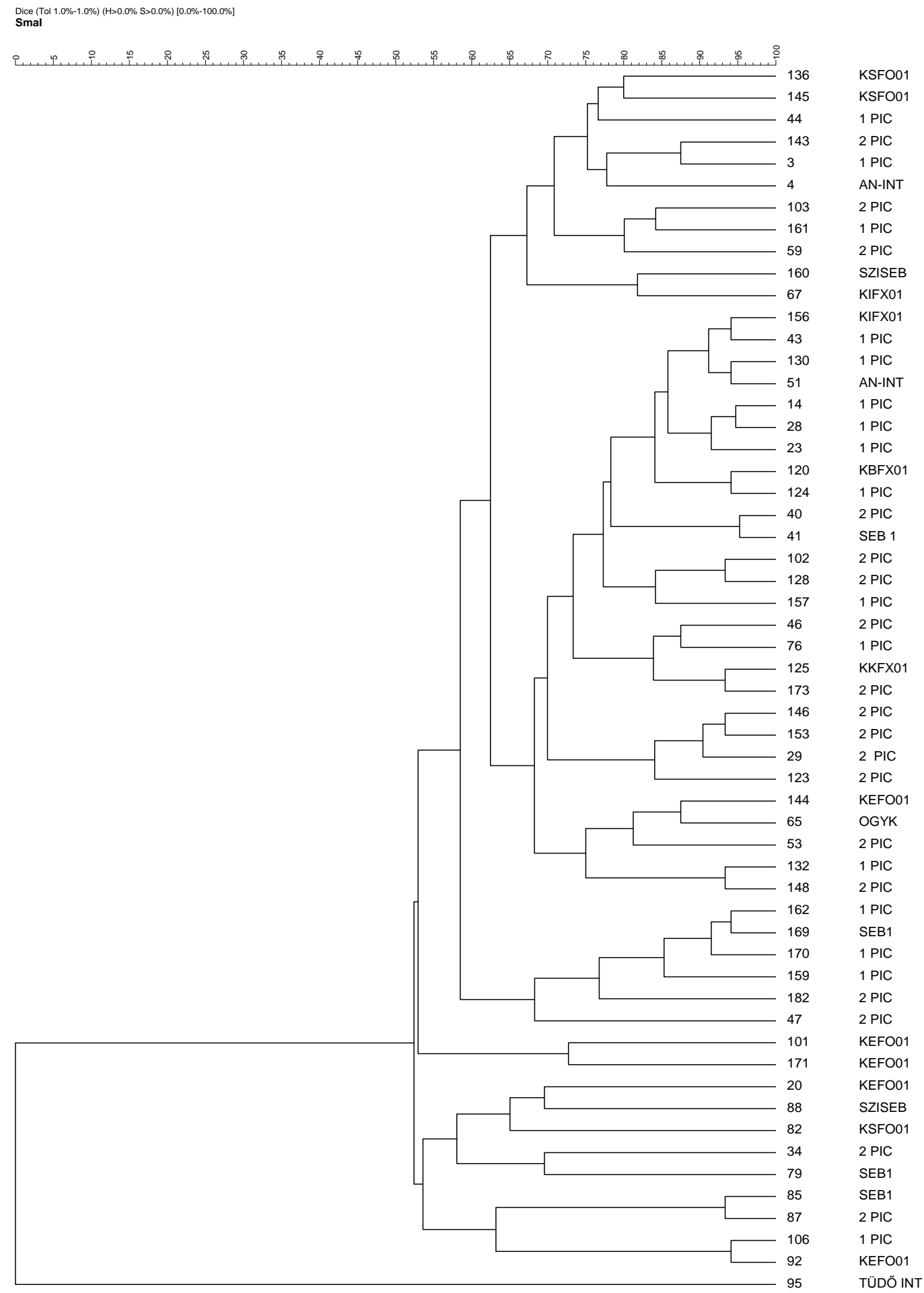


Table 1 - Distribution of pathogens associated with blood-stream infections in patients treated in the hospitals of the Semmelweis University between January 2001 and December 2008

\begin{tabular}{|c|c|c|c|c|c|c|c|c|c|c|}
\hline & 2001 & 2002 & 2003 & 2004 & 2005 & 2006 & 2007 & 2008 & \multicolumn{2}{|c|}{ Together } \\
\hline Pathogen & $\%$ & $\%$ & $\%$ & $\%$ & $\%$ & $\%$ & $\%$ & $\%$ & number & $\%$ \\
\hline Total number & 272 & 369 & 448 & 527 & 449 & 235 & 309 & 348 & 2967 & 100 \\
\hline All Gram-positive & 41 & 49 & 60 & 53 & 63 & 59 & 68 & 59 & 1679 & 57 \\
\hline Staphylococcus aureus & 8 & 11 & 11 & 12 & 12 & 11 & 15 & 15 & 354 & 12 \\
\hline Staphylococcus haemolyticus & 4 & 6 & 10 & 5 & 8 & 5 & 5 & 5 & 184 & 6 \\
\hline Staphylococcus epidermidis & 16 & 18 & 22 & 19 & 22 & 22 & 28 & 19 & 613 & 21 \\
\hline Other CoNS & 4 & 5 & 5 & 3 & 4 & 7 & 6 & 8 & 149 & 5 \\
\hline Streptococci & 2 & 2 & 1 & 4 & 3 & 6 & 6 & 4 & 103 & 3 \\
\hline Enterococci & 7 & 7 & 10 & 8 & 12 & 8 & 6 & 8 & 255 & 9 \\
\hline Other Gram-positive & 0 & 0 & 0 & 1 & 1 & 0 & 2 & 1 & 21 & 1 \\
\hline All Gram-negative & 53 & 44 & 35 & 42 & 33 & 37 & 28 & 37 & 1143 & 39 \\
\hline Escherichia coli & 11 & 13 & 12 & 14 & 13 & 13 & 10 & 15 & 381 & 13 \\
\hline KES group & 25 & 14 & 11 & 11 & 9 & 11 & 7 & 11 & 359 & 12 \\
\hline Proteus spp. & 2 & 1 & 1 & 1 & 1 & 1 & 1 & 1 & 37 & 1 \\
\hline Pseudomonas spp. & 9 & 9 & 6 & 9 & 6 & 8 & 5 & 7 & 224 & 8 \\
\hline Acinetobacter spp. & 4 & 4 & 2 & 3 & 2 & 3 & 1 & 1 & 76 & 3 \\
\hline Stenotrophomonas maltophilia & 1 & 2 & 1 & 2 & 1 & 0 & 1 & 0 & 34 & 1 \\
\hline Other gram-negative & 1 & 1 & 1 & 1 & 1 & 0 & 2 & 1 & 32 & 1 \\
\hline Candida spp. & 6 & 7 & 5 & 5 & 4 & 4 & 4 & 4 & 145 & 5 \\
\hline
\end{tabular}

CoNS = coagulase-negative staphylococci

KES = Klebsiella spp., Enterobacter spp., Citrobacter spp. and Serratia spp. 
Table 2 - Incidence of Staphylococcus haemolyticus among isolates causing bacteriaemia according to care units examined in the years $2001-2008$

\begin{tabular}{|l|c|c|c|}
\hline Department & Total bacteriaemia & \multicolumn{2}{|c|}{ S. haemolyticus bacteriaemia } \\
\hline & $\mathrm{n}$ & $\mathrm{n}$ & $\mathbf{\%}$ \\
\hline Internal Medicine 1 & 196 & $\mathbf{4}$ & $\mathbf{2 , 0}$ \\
\hline Internal Medicine 2 & 405 & $\mathbf{8}$ & $\mathbf{2 , 0}$ \\
\hline Internal Medicine 3 & 137 & $\mathbf{1}$ & $\mathbf{0 , 7}$ \\
\hline Internal Medicine 4 & 129 & $\mathbf{3}$ & $\mathbf{2 , 3}$ \\
\hline Pulmonology & 143 & $\mathbf{1}$ & $\mathbf{0 , 7}$ \\
\hline Surgery 1 & 131 & $\mathbf{7}$ & $\mathbf{5 , 3}$ \\
\hline Surgery 2 & 101 & $\mathbf{6}$ & $\mathbf{5 , 9}$ \\
\hline Cardiac surgery & 713 & $\mathbf{2 8}$ & $\mathbf{3 , 9}$ \\
\hline Intensive Care Unit 1 & 125 & $\mathbf{5}$ & $\mathbf{4 , 0}$ \\
\hline Intensive Care Unit 2 & 80 & $\mathbf{3}$ & $\mathbf{3 , 8}$ \\
\hline Neonatal Intensive Care Unit 1 & 352 & $\mathbf{6 4}$ & $\mathbf{1 8 , 2}$ \\
\hline Neonatal Intensive Care Unit 2 & 348 & $\mathbf{5 1}$ & $\mathbf{1 4 , 7}$ \\
\hline Others & 107 & $\mathbf{3}$ & $\mathbf{2 , 8}$ \\
\hline Total & $\mathbf{2 9 6 7}$ & $\mathbf{1 8 4}$ & $\mathbf{6 , 2}$ \\
\hline
\end{tabular}


Table 3 - Prevalence of resistance to antistaphylococcal agents in invasive Staphylococcus haemolyticus strains

\begin{tabular}{|l|c|c|c|c|c|c|c|c|c|c|c|c|}
\hline Antibacterial agents & 2001 & 2002 & 2003 & 2004 & 2005 & 2006 & 2007 & 2008 & All & & & \\
\hline & $\mathrm{n}=10$ & $\mathrm{n}=22$ & $\mathrm{n}=44$ & $\mathrm{n}=26$ & $\mathrm{n}=38$ & $\mathrm{n}=12$ & $\mathrm{n}=15$ & $\mathrm{n}=17$ & total $\mathbf{n = 1 8 4}$ & range of MICs & MIC50 & MIC90 \\
\hline & $\%$ & $\%$ & $\%$ & $\%$ & $\%$ & $\%$ & $\%$ & $\%$ & $\mathbf{\%}$ & & & \\
\hline oxacillin & 90 & 100 & 96 & 96 & 100 & 92 & 93 & 100 & $\mathbf{9 7}$ & $4->256$ & $>256$ & $>256$ \\
\hline erythromycin & 100 & 95 & 96 & 100 & 100 & 92 & 87 & 94 & $\mathbf{9 6}$ & $1->256$ & 128 & $>256$ \\
\hline clindamycin & 70 & 82 & 66 & 65 & 45 & 50 & 47 & 76 & $\mathbf{6 2}$ & $2->256$ & $>256$ & $>256$ \\
\hline gentamicin & 80 & 91 & 89 & 85 & 89 & 75 & 87 & 94 & $\mathbf{8 7}$ & $2->256$ & 128 & $>256$ \\
\hline sulph./trimethoprim & 50 & 41 & 36 & 50 & 47 & 83 & 67 & 53 & $\mathbf{4 9}$ & $4->256$ & 128 & $>256$ \\
\hline doxycycline & 70 & 27 & 9 & 15 & 8 & 8 & 20 & 0 & $\mathbf{1 5}$ & $2-32$ & 2 & 8 \\
\hline ciprofloxacin & 50 & 73 & 84 & 88 & 97 & 83 & 80 & 88 & $\mathbf{8 4}$ & $<0,5->256$ & 64 & 128 \\
\hline levofloxacin & 50 & 73 & 83 & 88 & 97 & 83 & 80 & 88 & $\mathbf{8 1}$ & $<0,5-64$ & 16 & 32 \\
\hline moxifloxacin & 50 & 73 & 82 & 88 & 95 & 83 & 80 & 88 & $\mathbf{7 9}$ & $0,064-16$ & 2 & 8 \\
\hline linezolid & 0 & 0 & 0 & 0 & 0 & 0 & 0 & 0 & $\mathbf{0}$ & $0.25-0.5$ & 0.38 & 0.5 \\
\hline vancomycin & 0 & 0 & 0 & 0 & 0 & 0 & 0 & 0 & $\mathbf{0}$ & $1-2$ & 1 & 2 \\
\hline teicoplanin & 10 & 14 & 11 & 15 & 10 & 16 & 20 & 23 & $\mathbf{1 3}$ & $2-32$ & 4 & 32 \\
\hline
\end{tabular}


Table 4 - The predominant phenotypical antibiotic resistance patterns of

\section{Staphylococcus haemolyticus strains}

\begin{tabular}{|l|l|c|c|}
\hline pattern type & \multicolumn{1}{|c|}{ resistance pattern } & number & $\%$ \\
\hline 4a & OX, E, CL, GE & 8 & 4.35 \\
\hline $4 \mathrm{f}$ & OX, E, GE, CIP & 24 & 13.04 \\
\hline $5 \mathrm{c}$ & OX, E, CL, GE, CIP & 35 & 19.02 \\
\hline $5 \mathrm{e}$ & OX, E, GE, SXT, CIP & 29 & 15.76 \\
\hline 6b & OX, E, CL, GE, SXT, CIP & 37 & 20.01 \\
\hline $7 \mathrm{a}$ & OX, E, CL, GE, SXT, DO, CIP & 10 & 5.43 \\
\hline Together & \multicolumn{2}{|c}{} \\
\hline
\end{tabular}

Abbreviation: $\mathrm{OX}=$ oxacillin, $\mathrm{E}=$ erythromycin, $\mathrm{CL}=$ clindamycin,

$\mathrm{GE}=$ gentamicin, $\mathrm{SXT}=$ sulfamethoxazole/trimethoprim, $\mathrm{DO}=$ doxycycline, $\mathrm{CIP}=$ ciprofloxacin 45. 